\title{
Pathogenesis of Nodular Histiocytic Hyperplasia in Serous Effusions
}

Dear Dr. Bedrossian:

I would like to offer an explanation as to how the nodules of so-called nodular histiocytic hyperplasia ( $\mathrm{NHH}$ ) form in some specimens of pleural, peritoneal, and pericardial fluid. Such nodules were well-illustrated by Drs. Choi and Song in their recently published article in Diagnostic Cytopathology. ${ }^{1}$ They demonstrated that these nodules are composed of compact aggregates of histiocytes, which may contain the occasional mesothelial cell.

In cell block preparations, these tightly packed aggregates (nodules) of histiocytes are always bounded by a band of fibrin. The bands may be thin and scarcely visible as in Figure 4 of Drs. Choi and Song, or they may be thick, as in their Figure 3. ${ }^{1}$ Obviously, fluid manifesting NHH has to contain numerous histiocytes, and it must also contain fibrin, which may have formed spontaneously before or after the fluid was aspirated. In smears of serous fluids, histiocytes are often seen in irregularly shaped, loose aggregates, presumably because of their long microvilli. Such aggregates become enmeshed by fibrin in the fluid, which contracts around them to create densely packed, well-circumscribed nodules. Smear preparations do not exhibit the well-defined nodules of $\mathrm{NHH}$, presumably because any histiocytic aggregates become disrupted by the smearing technique.

In cell blocks, the dense and smoothly contoured aggregates of histiocytes may be mistaken for fragments of carcinoma. A superb example of this is featured in the chapter on cytology of serous fluids in both editions of Bibbo's Comprehensive Cytopathology. The patient, a young woman, was referred to our hospital with a diagnosis of metastatic adenocarcinoma in her pleural effusion. And recently I reviewed a specimen in litigation that had been misdiagnosed as metastatic adenocarcinoma in pleural fluid; again, it was an example of NHH. Obviously, this morphologic entity is a most important pitfall of cytodiagnosis of serous fluids.

Bernard Naylor, M.D. Department of Pathology University of Michigan

Ann Arbor, Michigan

\section{References}

1. Choi Y-L, Song S-Y. Cytologic clue of [sic] so-called nodular histiocytic hyperplasia of the pleura. Diagn Cytopathol 2001;24:256-259. 